\title{
Predictors of students' perceived learning in off-campus learning environment: Online interactions are not enough
}

\author{
David Kwok \\ Republic Polytechnic
}

\begin{abstract}
This study aimed to investigate how three online interaction variables (i.e., learner-instructor interaction, learner-content interaction, and learner-learner interaction) and self-efficacy for learning can predict students' perceived learning in an off-campus learning environment. A total of 654 polytechnic students participated in the study. By controlling gender and age, regression results showed that self-efficacy for learning was the significantly strongest predictor of perceived learning, followed by learner-content interaction. Perceived learning and learner-instructor interaction for males were significantly higher than females. Finally, implications of these findings along with limitations of the study and directions for future research are discussed in the paper.
\end{abstract}

Keywords: Online interactions, self-efficacy, perceived learning, off-campus learning

\section{Introduction}

The COVID-19 has brought about unprecedented disruptions to education. With the sudden surge of remote online learning courses offered by many higher education institutions, it is of utmost importance for educators and policy makers to evaluate how students perceived their learning to improve the quality of these online courses in terms of the design, delivery and evaluation which ultimately translate into enhancing students' learning experience (Alqurashi, 2019).

According to Moore (1989), there are three types of interactions required for effective online learning: (a) learner-content interaction (LCI), (b) learner-instructor interaction (LII), and (c) learner-learner interaction (LLI). LCI refers to how students interact with the course content or subject matter. LII refers to the two-way communication between students and instructor. LLI is a two-way communication between and among learners to exchange ideas or information related to course content or completing a group task.

A critical component in online learning is self-efficacy (SE) which is defined as 'the level of confidence that someone has to perform a particular task, activity, action or challenge' (Alqurashi, 2016, p. 45).

When learners believe that they can achieve results, they will make efforts to take the necessary steps to overcome obstacles to achieving and developing skills that could enhance their learning and performance.

Perceived learning (PL) was selected as an outcome of this study as it has been considered as an indicator of students' learning, and one of the core elements for online course evaluation (Wright, Sunal, \& Wilson, 2006). Perceived learning is defined as learners' judgment that their knowledge and understanding are constructed (Rovai, 2002).

As part of the business continuity management initiative, the institution participating in this study implemented a one-week off-campus learning (OCL) in July 2019 to prepare for crisis management such as the pandemic, fire or hazardous haze situation where students could continue to learn from home. This evaluation study is an attempt to investigate whether the three online interaction variables and self- efficacy for learning (SE) can predict students' perceived learning (PL) within an OCL environment.

\section{Literature Review}

In a meta-analysis of 74 studies on distance learning courses, Bernard et al. (2009) found that the three types of interactions (i.e., LLI, LII, and LCI) were positively associated with academic achievement outcomes. However, these researchers cautioned that effective interactions occurred only when learning and instructions are well designed and implemented, and it is about quality interactions and not quantity that matters. 
Besides having effective online interactions, it is also important that students acquired confidence in completing learning tasks, and to investigate if these factors influence changes in students' perceptions of skills and knowledge levels during online lessons. A number of studies conducted in various university settings have examined the relationships among three online interactions, self-efficacy for learning and perceived learning. For example, studies have shown the LII was the most significant predictor of students' perceived learning (e.g., Fredericksen et al., 2000; Jiang \& Ting, 2000). However, Alqurashi (2019) found that among the three online interaction variables, LLI did not predict students' perceived learning but LCI and LII did. In the same study, online learning self-efficacy was the strongest and most significant predictor of perceived learning, followed by LII and LCI.

In a recent study, Kara, Kukul, and Cakir (2020) found that except for LII, both LCI and LLI were significant predictors of perceived learning. LCI was the strongest predictor of perceived learning. Mean perceived learning score for females was significantly higher than males, and path analysis showed that LCI and LLI were significant predictors for females, whereas only LLI predicted perceived learning for males (Kara et al., 2020).

As there is limited research on the effects of self-efficacy for learning and online interactions on students' perceived learning within the OCL environment in the polytechnic, this study is an attempt to fill the gap. Results of this study could provide meaningful insights for polytechnic educators to improve the design, delivery and evaluation of future OCL courses which will enhance students' online learning experience.

\section{Objectives of Study}

This study aimed to investigate the effects of online interactions and self-efficacy for learning on students' perceived learning, and examined if gender differences exist among these variables and their relationships.

Specifically, the following research questions were formulated to guide the data analysis:

1. To what extent do the three online interaction variables (i.e., LII, LCI, and LLI) predict students' perceived learning?

2. To what extent does self-efficacy for learning explain students' perceived learning above and beyond what is already explained by the other three online interaction variables (i.e., LII, LCI, and LLI)?

3. Do gender differences exist in the perceptions of study variables (i.e., LII, LCI, LLI, SE, and PL) and their relationships?

\section{Method}

Participants were 654 first-year polytechnic students in Singapore taking a foundational module on 'Critical Thinking and Problem Solving'. 48.8\% of the students were female and 51.2\% were male. Their mean age was 18.33 years $(\mathrm{SD}=1.26)$. Convenience sampling was employed and students participated in an online questionnaire which was administered during the one-week OCL. During the OCL lessons, the students accessed, curated, and evaluated the online learning content from the Polytechnic's Learning Management System, and used an array of technology-enhanced learning (TEL) tools to interact, communicate and collaborate with each other to complete learning tasks.

The online questionnaire used various scales drawn from empirical studies related to online interactions, selfefficacy and perceived learning. Three subscales were adapted from Cho and Cho (2017)'s online selfregulation questionnaire, i.e., LCI subscale (11 items), LII subscale (9 items) and LLI subscale (9 items). A 6item self-efficacy for learning scale adapted from Artino (2007) and a 4-item perceived learning scale was adapted from Kurucay and Inan (2017). Sample items included "I planned my time to complete assignments in this online lesson (LCI)", "I sought assistance from the lecturer if I needed it (LII)", "I regularly interacted with other students in this online lesson (LLI)", and "I am certain I understood the most difficult material presented in the online lesson (SE)" and "I gained mastery of the materials presented online (PL)". All the items were rated on a 5-point Likert scale, ranging from ' $1=$ strongly disagree' to ' $5=$ strongly agree'. This research was approved by the Ethics Review Committee at the institution where the study was undertaken. 


\section{Results}

Table 1 presented the correlations among the 5 variables and reliabilities. All of the correlation coefficients were positive and significant $(.44 \leq \mathrm{r} \leq .82 ; \mathrm{p}<.01)$. The Cronbach's alpha coefficient which is a measure of internal consistency reliability for the 5 variables ranged between .91 and .95 , all at the excellent levels.

Table 1. Descriptive statistics, correlations and reliabilities

\begin{tabular}{|c|c|c|c|c|c|c|c|}
\hline \multirow[t]{2}{*}{ Variables } & \multirow[t]{2}{*}{ M } & \multirow[t]{2}{*}{ SD } & \multicolumn{5}{|c|}{ Bivariate Correlations } \\
\hline & & & 1 & 2 & 3 & 4 & 5 \\
\hline 1. Learner-Instructor Interaction (LII) & 3.89 & .66 & $(.95)$ & & & & \\
\hline 2. Leamer-Content Interaction (LCI) & 3.93 & .54 & $.58 * *$ & (.91) & & & \\
\hline 3. Leamer-Leamer Interaction (LII) & 4.11 & .57 & $61^{* *}$ & $68 * *$ & $(.92)$ & & \\
\hline 4. Self-Efficacy for Learning (SE) & 3.76 & .74 & $.51 * *$ & $.56^{* *}$ & $61^{* *}$ & $(.94)$ & \\
\hline 5. Perceived Leaming (PL) & 3.80 & .77 & $.44^{* *}$ & $.52^{* *}$ & $.56^{* *}$ & $.82^{* *}$ & $(.94)$ \\
\hline
\end{tabular}

To answer research question 2 and 3, hierarchical multiple regression analysis was used with perceived learning as the dependent variable (see Table 2). In step 1 of Model 1, to control demographic variables, age and gender were entered. These demographics variables accounted for $3 \%$ of the variance of perceived learning. The three interaction variables were entered in step 2 , followed by self-efficacy for learning in step 3 . The results indicated that in Model 2, all the three interaction variables were significant predictors of perceived learning, with LCI being the highest significant predictor of perceived learning $(\beta=.38, \mathrm{p}<.01)$, followed by LLI $(\beta=.21, \mathrm{p}<.01)$ and LII $(\beta=.11, \mathrm{p}<.01)$. The three interaction variables explained for $45 \%$ of the variance in perceived learning.

In Model 3, SE was the highest significant predictor of perceived learning $(\beta=.73, p<.01)$, followed by LCI as the significant predictor of perceived learning $(\beta=.08, \mathrm{p}<.05)$. The addition of SE in Model 2 contributed to an additional $24 \%$ of the total $73 \%$ variance in perceived learning.

Table 2. Hierarchical multiple regression results for perceived learning

\begin{tabular}{lccc}
\hline & \multicolumn{2}{c}{ Dependent Variable = Perceived Learning } \\
\cline { 2 - 4 } & Model 1 & Model 2 & Model 3 \\
\hline Demographics & $-.12^{* *}$ & $-.08^{* *}$ & -.04 \\
- Gender & $-.16^{* *}$ & $-.10^{* *}$ & $-.05^{*}$ \\
- Age & & & \\
Main Effects & & $.17^{* *}$ & .04 \\
- Learner-Instructor Interaction (LII) & & $.38^{* *}$ & $.08^{*}$ \\
- Learner-Content Interaction (LCI) & & $.21^{* *}$ & .04 \\
- Learner-Learner Interaction (LLI) & 10.76 & 122.74 & $.73^{* *}$ \\
- Self-Efficacy for Learning (SE) & .03 & .48 & 288.27 \\
F & .03 & .45 & .73 \\
Adjusted $\mathrm{R}^{2}$ & & & .24 \\
$\Delta \mathrm{R}^{2}$ & &
\end{tabular}

To answer research question 3, an independent sample t-test was used to investigate how participant perceptions of variables vary depending on gender (see Table 3 ). The results showed perceived learning scores of males (M $=3.86, \mathrm{SD}=.77)$ was significantly higher than females $(\mathrm{M}=3.73, \mathrm{SD}=.76)$, and the effect size of .18 was at a small level. The results also revealed that the LII scores for males $(\mathrm{M}=3.94, \mathrm{SD}=3.83)$ was significantly higher than females $(\mathrm{M}=3.83, \mathrm{SD}=.66)$, with a small effect size of .16 . Next, a multiple regression analysis was separately tested for males and females to determine the significant predictors of perceived learning. The result showed that self-efficacy for learning remained the strongest significant predictor of students' perceived learning for both the gender groups. Among the three online interaction variables, perceived learning of males was significantly influenced by LII $(\beta=.03, \mathrm{p}<.05)$ whereas LCI significantly predicted perceived learning of females $(\beta=.12, \mathrm{p}<.05)$. 
Table 3. Independent sample t-test results by gender comparison of study variables

\begin{tabular}{lllllll}
\hline & Gender & $\mathrm{N}$ & $\mathrm{M}(\mathrm{SD})$ & t-value & $\begin{array}{l}\text { Sig. (2- } \\
\text { tailed) }\end{array}$ & $\begin{array}{l}\text { Effect } \\
\text { Size }\end{array}$ \\
\hline Learner-Instructor Interaction (LII) & Male & 335 & $3.94(.66)$ & 2.17 & $.03 *$ & .16 \\
& Female & 319 & $3.83(.66)$ & & & \\
Learner-Content Interaction (LCI) & Male & 335 & $3.95(.54)$ & 1.18 & .24 & \\
& Female & 319 & $3.90(.55)$ & & & \\
Learner-Learner Interaction (LLI) & Male & 335 & $4.10(.59)$ & -.50 & .62 & \\
& Female & 319 & $4.12(.55)$ & & & .18 \\
Self-Efficacy for Learning (SE) & Male & 335 & $3.81(.75)$ & 1.83 & .07 & \\
& Female & 319 & $3.70(.73)$ & & & \\
Perceived Learning (PL) & Male & 335 & $3.86(.77)$ & 2.29 & $.02 *$ & \\
& Female & 319 & $3.73(.76)$ & & & \\
\hline
\end{tabular}

$* \mathrm{p}<.05$

\section{Discussion}

This study attempted to investigate how the four independent variables (LII, LCI, LLI, and SE) predicted outcome variable on students' perceived learning in an OCL environment, and if gender differences exist among these variables and their relationships. There are three noteworthy findings in this study.

First, LCI was the highest significant predictor of students' perceived learning among the three interaction variables. Students engaged in OCL lessons typically spent a lot of time curating, selecting, processing and evaluating online learning content themselves. This raises the question of whether instructors should play a more active role in promoting greater dialogue with students, and among students, thereby reducing students' feelings of anxiety and isolation during the OCL lessons.

Second, the result showed that the addition of self-efficacy for learning to the three online interaction variables have resulted in a more robust model for predicting students' perceived learning, consistent with Alqurashi (2019)'s study finding. Self-efficacy for online learning can be enhanced in many ways. One key recommendation is to develop students' confidence using TEL tools such as Padlet, Mind Mapping tool, and Microsoft Office tools before the OCL lessons to improve their communication, online interactions and collaborative learning. In addition, instructors could also help to build students' confidence in their abilities to learn on their own, learn collaboratively with their peers and complete learning tasks successfully through providing timely and constructive feedback to them.

Third, the result indicated that perceived learning among males were significantly higher than females, inconsistent with the study findings by Kara et al. (2020). There is also empirical evidence that showed males were more inclined to adopt learner-instructor interactions than females during the lessons. Based on my observation, one plausible reason is that males seemed to be more participative and proactive in their interactions with their peers as well as instructor compared to females. Hence, instead of eliciting voluntary participation from the class, instructors could design learning activities that encourage more interactions with and participation from female students to improve the overall class engagement and students' perceived learning in future online lessons.

\section{Limitations and Future Research}

This study is not without limitations. Firstly, study does not show how the three interaction variables interact simultaneously with each other, and how these could influence self-efficacy for learning and perceived learning. Future research could employ structural equation modelling to test the relationships of these variables in a model to improve its predictive power in the study. Secondly, the types of interaction provided for the various teaching tasks differ by subject areas, and for learners at different stages of development (Moore, 1989). Thus, including different subject areas and diverse participants in the fully online learning environment can be considered in future investigations. Finally, the study focused on students' learning in a fully online lesson in an OCL environment. Hence, we caution generalizing the findings in other learning settings. Future research can be 
undertaken in the blended learning environment to better understand the relationships among student interactions, self-efficacy for learning and perceived learning between face-to-face and online mode of learning.

\section{Conclusion}

In conclusion, this study provided empirical evidence that online interactions are not enough to predict students' perceived learning, and the addition of self-efficacy for learning can help to improve its predictability. There is also evidence of gender differences in the perception online interaction variables, and how these predicted students' perceived learning. The findings in this study could help educators in the advancement of knowledge on the design, delivery and evaluation of an online lesson in an OCL environment which ultimately enhances students' learning experiences.

\section{References}

Alqurashi, E. (2016). Self-efficacy in online learning environments: A literature review. Contemporary Issues in Education Research, 9(1), 45-51.

Alqurashi, E. (2019). Predicting student satisfaction and perceived learning within online learning environments. Distance Education, 40(1), 133-148.

Artino Jr, A. R. (2007). Online military training: Using a social cognitive view of motivation and selfregulation to understand students' satisfaction, perceived learning, and choice. Quarterly Review of Distance Education, 8(3), 191.

Bernard, R. M., Abrami, P. C., Borokhovski, E., Wade, C. A., Tamim, R. M., Surkes, M. A., \& Bethel, E. C. (2009). A meta-analysis of three types of interaction treatments in distance education. Review of Educational Research, 79(3), 1243-1289.

Cho, M.-H., \& Cho, Y. (2017). Self-regulation in three types of online interaction: A scale development. Distance Education, 38(1), 70-83.

Fredericksen, E., Pickett, A., Shea, P., Pelz, W., \& Swan, K. (2000). Student satisfaction and perceived learning with online courses: Principles and examples from the SUNY learning network. Journal of Asynchronous Learning Networks, 4(2), 7-41.

Jiang, M., \& Ting, E. (2000). A study of factors influencing students' perceived learning in a web-based course environment. International Journal of Educational Telecommunications, 6(4), 317-338.

Kara, M., Kukul, V., \& Cakır, R. (2020). Self-regulation in Three Types of Online Interaction: How Does It Predict Online Pre-service Teachers' Perceived Learning and Satisfaction? Asia-Pacific Education Researcher.

Kurucay, M., \& Inan, F. A. (2017). Examining the effects of learner-learner interactions on satisfaction and learning in an online undergraduate course. Computers \& Education, 115, 20-37.

Moore, M. G. (1989). Editorial: Three types of interaction. American Journal of Distance Education, 3(2), 17.

Rovai, A. P. (2002). Sense of community, perceived cognitive learning, and persistence in asynchronous learning networks. The Internet and Higher Education, 5(4), 319-332.

Wright, V. H., Sunal, C. S., \& Wilson, E. K. (2006). Research on enhancing the interactivity of online learning. Greenwich, CT: Information Age Publishing Inc.

Kwok, D. (2020). Predictors of students' perceived learning in off-campus learning environment: Online interactions are not enough. In S. Gregory, S. Warburton, \& M. Parkes (Eds.), ASCILITE's First Virtual Conference. Proceedings ASCILITE 2020 in Armidale (pp. 241-245). https://doi.org/10.14742/ascilite2020.0114

Note: All published papers are refereed, having undergone a double-blind peer-review process.

The author(s) assign a Creative Commons by attribution licence enabling others to distribute, remix, tweak, and build upon their work, even commercially, as long as credit is given to the author(s) for the original creation.

(C) Kwok, D. 2020 